\title{
CASA in invertebrates
}

\author{
Gerhard van der Horst, Monique Bennett and John D. D. Bishop
}

\begin{abstract}
Sperm movement has been described in several phyla of invertebrates. Yet, sperm motility has only been quantified using computer-aided sperm analysis (CASA-Mot) in externally fertilising species (broadcast spawners) of two phyla, molluscs and echinoderms. In the present study we quantified in detail the nature of the sperm tracks, percentage motility groupings and detailed kinematics of rapid-, medium- and slow-swimming spermatozoa in the oyster Crassostrea gigas and four species never previously studied by CASA-Mot, namely the molluscs Choromytilus meridionalis, Donax serra and Haliotis midae and the echinoderm Parechinus angulosus. A feature common to all these species are the helical tracks, the diameter of which seems to be species specific. Using CASA-Mot, the behaviour of spermatozoa was also studied over time and in the presence of egg water and $\mathrm{Ca}^{2} \mathrm{p}$ modulators such as caffeine and procaine hydrochloride. For the first time, we show that hyperactivation can be induced in all species in the presence of egg water (sea water that was mixed with mature eggs and then centrifuged) and/or caffeine, and these hyperactivated sperm tracks were characterised using CASA-Mot. We relate the different patterns of sperm motility and behaviour to reproductive strategies such as broadcast spawning and spermcasting, and briefly review studies using CASA-Mot on other invertebrates.
\end{abstract}

\section{Introduction}

The invertebrates comprise over 30 phyla, plus the subphylum Tunicata within the Chordata. The Phylum Arthropoda is by far the most speciose, insects alone making up 95\% of living animal species; insect fertilisation is internal, and the use of computer-aided sperm analysis (CASA) of insect spermatozoa has been very limited (but see Pearcy et al. 2014). Invertebrate diversity at the phylum level is greatest in the sea, and the variety of reproductive patterns in aquatic invertebrates is vast. Nevertheless, three main routes to fertilisation can be recognised: copulation, broadcast spawning and spermcasting; these correspond to functional categories of spermatozoa proposed by Rouse and Jamieson (1987) and Jamieson and Rouse (1989), namely introsperm, ect-aquasperm and ent-aquasperm respectively. Copulation, involving the direct transfer of an ejaculate into the female without external exposure, is also prevalent in terrestrial invertebrates. The remaining two mechanisms are exclusively aquatic. 
Broadcast spawning is the release of both eggs and spermatozoa into the water for external fertilisation, whereas sperm-casting involves the release of spermatozoa only, to disperse to recipients that have retained their eggs. Broadcast spawning is a long-recognised means of fertilisation in the sea, but spermcast mating was not overtly acknowledged as a distinct process until relatively recently (see Pemberton et al. 2003; Bishop and Pemberton 2006), although it was recognised and documented, for example by Daly and Golding (1977), and implicitly acknowledged in various other studies. As noted by Bishop and Pemberton (2006), it is possible to envisage a continuum between spermcast mating and broadcast spawning. This was re-emphasised by Havenhand and Styan (2010), noting that some species fertilise their retained ova in a seawater-filled concavity, such as the mantle of a flat (brooding) oyster (Ostreinae), through which water is pumped rather than in a true body cavity. There are few studies of the behaviour of spermcast spermatozoa (entaquasperm), even counting those on commercial flat oysters. In contrast, studies of the behaviour and performance of ect-aquasperm, including by CASA, are more numerous, although all concern species of two phyla, Mollusca and Echinodermata. In many cases these studies involve commercially exploited species such as cupped (non-brooding) oysters (Crassostreinae), mussels (Mytilidae) and abalone (Haliotis spp.).

Original CASA-generated data are presented in this paper on the sperm performance and behaviour of five marine invertebrates from broadcast-spawning taxa. The five species investigated are classified under Mollusca and Echinodermata, and we offer some additional observations on Insecta and Crustacea.

Globally, the research focus in CASA-Mot was unfortunately largely limited to the former two phyla, with many papers reporting on mussels and sea urchins (e.g. Au et al. 2001; Fitzpatrick et al. 2010; Fabbrocini et al. 2010, 2016; Basti et al. 2013; Suquet et al. 2013). Surprisingly, almost no detailed CASA research has been performed in other invertebrate phyla and accordingly our title falls short of expectations. Previous surveys of the available data have suggested that spermcast spermatozoa are long lived compared with broadcastspawned spermatozoa, perhaps because of quiescence following release until reaching a conspecific recipient (Bishop 1998; Manríquez et al. 2001; Johnson and Yund 2004), although the spermatozoa of broadcast spawners may also be quiescent upon release, being activated by proximity to the egg or signals derived from it (e.g. Morita et al. 2006). In the present study we provide, in a systematic way, very detailed CASA-Mot analysis involving sperm concentration, percentage motility groupings and eight kinematic parameters of five broadcast spawners, some of which may show adaptations to highly waveswept environments. The data provided is the first comprehensive comparison of CASAMot baseline data among these broadcast spawners. In addition, we analyse in greater depth the nature of the typical helical swimming tracks and the implications this may have for rates of encounter with oocytes. Furthermore, we provide results of CASA analysis of sperm motility in the presence of egg water in the Cape sea urchin Parechinus angulosus (see Table 1), with comments on two other species studied as well as the effect of classical hyperactivation stimulants on sperm motility in two species. Hyperactivation of spermatozoa has been considered as a landmark of capacitation and fertilisation success (Mortimer 1997; 
Mortimer et al. 2015). Finally, we assess the use of CASA-Mot in estimating the concentration of immotile spermatozoa in a prawn species and the potential movement of the spike attached to the acrosome in this species. We also review important aspects of subjective sperm motility assessment in other invertebrate phyla in the Results and Discussion sections.

\section{Materials and methods Species studied}

Six marine invertebrates from three phyla were studied and are listed in Table 1. A permit for hand collection of species was obtained through the Department of Agriculture, Forestry and Fisheries, Cape Town, South Africa. Ten to twenty animals per species were used for the different motility studies, with the actual numbers indicated in the relevant tables.

\section{Animal collection and maintenance}

Commercially grown oyster Crassostrea gigas (new accepted genus Magellana), black mussel (Choromytilus meridionalis), abalone (Haliotis midae) and tiger prawn (Penaeus monodon) were obtained from mariculture farms; sea urchins (Parechinus angulosus) were hand collected at monthly low tides, between 2014 and 2017 from intertidal rock pools at Bloubergstand, Cape Town. During spring tide lows, the burrowing white mussels (Donax serra) were dug out by hand along the mean tide level of the exposed sandy beach at Big Bay, Cape Town. All animals were kept in aerated holders filled with sea water at $17-18^{\circ} \mathrm{C}$ (sea water temperatures $12-19^{\circ} \mathrm{C}$ ). 


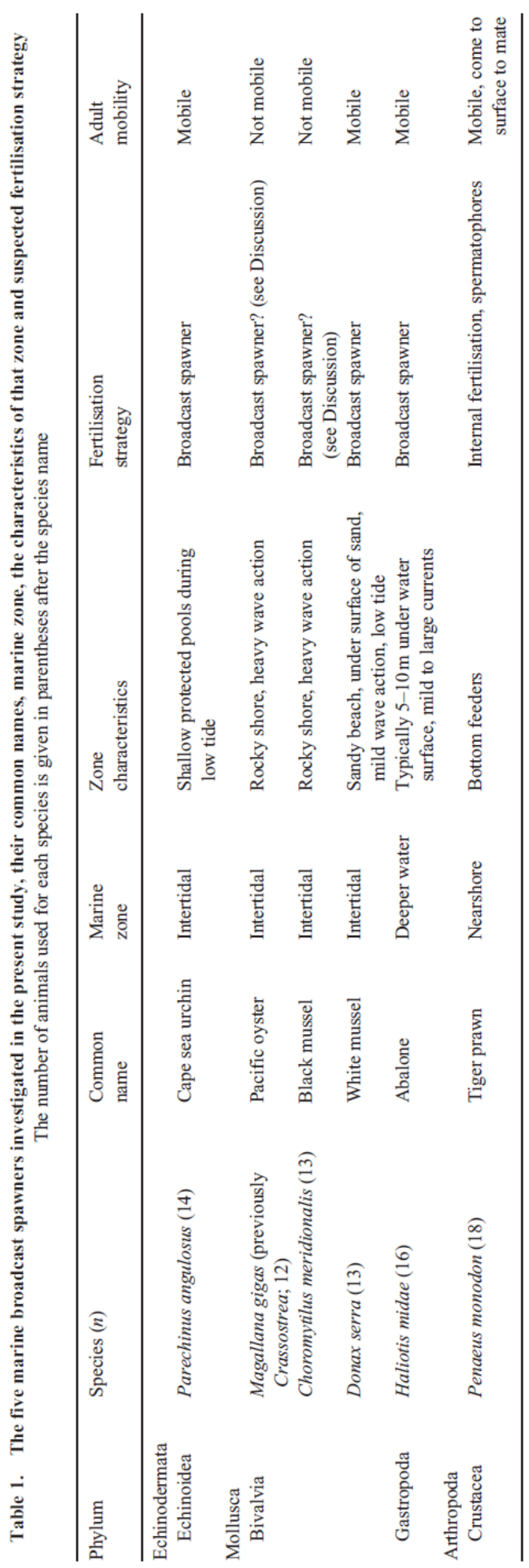




\section{Gamete collection}

Using a positive displacement pipette, spermatozoa were pipetted from the testes in the oyster and the two mussel species through an incision in the gonads and were dry stored in Eppendorf tubes. In $C$. meridionalis, we also tested the hypothesis that spermatozoa isolated from highly gravid testis for motility studies are similar to 'spawned' spermatozoa. Spawning was induced using a routine method (Stewart et al. 2012) and spermatozoa were immediately collected as close as possible to the mussel the moment it was ejected in the form of whitish clouds. This sperm-sea water suspension was placed in an Eppendorf tube and motility was studied by means of CASA-Mot for up to $90 \mathrm{~min}$ after spawning. These data were compared with the motility of spermatozoa isolated from gravid testes.

Gametes from sea urchin and abalone were obtained through chemically induced spawning. Sea urchins were given intracoelomic injections of 1-2 mL of $0.55 \mathrm{M} \mathrm{KCl}$, which caused spawning to be initiated within seconds to $5 \mathrm{~min}$, depending on the presence of gravid gonads. Female urchins, releasing orange eggs, were inverted onto a 100-mL beaker filled to the edge with filtered sea water, letting the aboral surface touch the water, allowing eggs to be freely ejected and settle at the bottom. This suspension was gently agitated and left to incubate for $20 \mathrm{~min}$; a volume of this egg-sea water suspension was centrifuged at $11 \mathrm{~g}$ for $5 \mathrm{~min}$ at $188 \mathrm{C}$. The supernatant liquid, egg water, was decanted into a clean Eppendorf tube and kept as a diluting medium for motility evaluation later. Eggs and surrounding egg water obtained from the ovaries of C. gigas and C. meridionalis were treated in the same way as for Parechinus to obtain egg water for sperm exposure studies.

Milky white spermatozoa being released from gonopores of $P$. angulosus were harvested and stored as 'dry spermatozoa' (undiluted) in an Eppendorf tube. Abalone broodstocks underwent a two-step chemical induction procedure as described by Morse et al. (1977), with a few adjustments. Sodium hydroxide was initially added to the spawning tanks, followed by hydrogen peroxide $15 \mathrm{~min}$ later. After $1 \mathrm{~h}$, these tanks were emptied, cleaned and refilled with aerated filtered sea water until males started spawning, generally $4 \mathrm{~h}$ after induction (Roux et al. 2014). Abalone spermatozoa were collected directly from the spawning tank, close to the respiratory pores located in the shell where the spermatozoa were ejected into sea water via the nephridiopore duct (Hahn 1989; and Purchon 1977), and stored in an Eppendorf tube.

\section{Preparation of motile spermatozoa}

Microscope analysis included measurement of sperm concentration, total motility and progressive motility in motile populations. In all instances, a 20-mm deep two-chamber Leja slide (Leja Products) was used. The motility of spermatozoa was determined following two techniques, flush and swim-up. Dry spermatozoa (undiluted spawned or neat spermatozoa sampled from the testis) from $P$. angulosus, $C$. meridionalis, $D$. serra and $C$. gigas were used for both the swim-up and flush techniques; $H$. midae samples were evaluated using only the flush technique for the chemically induced spawned gametes. 


\section{Flush technique}

The flush technique evaluates sperm motility at the inception of exposure to sea water in a chambered slide and, for most of the species, the concentrated sperm columns created allow spermatozoa to swim out. In contrast, for $H$. midae sperm motility using the flush technique was assessed from spawned samples in sea water (already mixed) and stored in an Eppendorf tube. A 5-mL aliquot of this sperm-sea water suspension was flushed in a 20-mm deep Leja slide for subsequent CASA-Mot analysis.

For $P$. angulosus, the flush technique involved collecting approximately $0.5^{-1} \mathrm{~mL}$ undiluted spawned spermatozoa and transferring the sample to a 20-mm deep two-chamber Leja slide (Leja Products). Through capillary action, a slight sperm dome was created at the mouth of the chamber (Leja 20-mm slide); to this, $5 \mathrm{~mL}$ filtered sea water was pipetted or flushed into the chamber, producing columns of spermatozoa in the chambered slide, and activated spermatozoa were recorded immediately using Sperm Class Analyser (SCA; Microptic) CASA-Mot software (see below).

For C. gigas, C. meridionalis and D. serra, dry spermatozoa (undiluted) were obtained directly from the testis and the same procedure as described for $P$. angulosus above was followed. We believe this technique best mimics what happens during actual spawning.

\section{Swim-uptechnique}

The swim-up technique was conducted individually for black mussel, white mussel, oyster and sea urchin dry spermatozoa using filtered sea water as a dilution medium. One part of dry spermatozoa from each of the samples was slowly pipetted, using a displacement pipette, forming a pellet at the bottom of an Eppendorf tube filled with five parts filtered sea water or egg water. Spermatozoa were usually inactive during the first 2 min upon dilution of testicular spermatozoa, but most spermatozoa became active after approximately $5 \mathrm{~min}$. In contrast, spawned spermatozoa became immediately active after dilution with sea water. Accordingly, a 10-min period of incubation resulted in spermatozoa swimming from the pellet into the column of sea water or egg water. As a result of the spermatozoa swimming from the pellet, a cloud developed in the fluid column. By pipetting $5 \mathrm{~mL}$ motile spermatozoa, taken from above the sperm cloud of the pellet, a slide was prepared using a 20mm deep two- chamber Leja slide. Sperm motility was recorded after 10 and 60 min.

\section{Effects of egg water and $\mathrm{Ca}^{2+}$ modulators}

In three species (sea urchin, black mussel, Pacific oyster), egg water was also used as a diluting medium and sperm motility was accordingly measured after exposure to egg water using the flush technique.

The effects of two $\mathrm{Ca}^{2+}$ modulators that induce hyperactivation in many animal species, namely caffeine $(10 \mathrm{mM})$ and procaine hydrochloride $(5 \mathrm{mM})$, were tested on $C$. meridionalis and C. gigas spermatozoa and compared with egg water using the flush technique. Accordingly, $0.5^{-1} \mathrm{~mL}$ undiluted spermatozoa was flushed with $5 \mathrm{~mL}$ filtered sea 
water containing either egg water or the $\mathrm{Ca}^{2+}$ modulators. Sperm motility was recorded after 10 and 60 min using the SCA CASA-Mot system (see below).

Table 2. Mean ( \pm s.d.) sperm concentration, percentage motility, percentage progressive motility and the percentage of non-progressive motility In all species, sperm concentration represents testicular samples, except in the case of Parechinus (collected at external gonopores), Haliotis (sperm collection took place during induced spawning) and Penaeus (collected from the spermatophore). Table 1 shows the numbers used for each species

\begin{tabular}{|c|c|c|c|c|c|}
\hline Species & $\begin{array}{c}\text { Concentration } \\
\left(\times 10^{6} \text { spermatozoa } \mathrm{mL}^{-1}\right)\end{array}$ & $\begin{array}{c}\text { Total } \\
\text { motility }(\%)\end{array}$ & $\begin{array}{c}\% \text { Rapid progressive } \\
\text { motility }\end{array}$ & $\begin{array}{c}\% \text { Medium progressive } \\
\text { motility }\end{array}$ & $\begin{array}{c}\% \text { Non-progressive } \\
\text { motility (slow) }\end{array}$ \\
\hline Parechinus angulosus & $5057.2 \pm 1353.3$ & $66.4 \pm 21.5$ & $46.7 \pm 23.4$ & $12.4 \pm 18.3$ & $7.3 \pm 8.4$ \\
\hline $\begin{array}{l}\text { Choromytilus } \\
\text { meridionalis }\end{array}$ & $3247 \pm 2027$ & $54.7 \pm 23.3$ & $26.8 \pm 18.8$ & $19.7 \pm 12.9$ & $8.2 \pm 9.6$ \\
\hline Donax serra & $4642 \pm 3702$ & $50.3 \pm 30.7$ & $43.4 \pm 31.1$ & $3.03 \pm 2.9$ & $4.0 \pm 4.1$ \\
\hline Penaeus monodon & $2893.9 \pm 1031.4$ & 0 & 0 & 0 & 0 \\
\hline
\end{tabular}

CASA equipment, acquisition properties and sperm functional parameters To divide spermatozoa into subpopulations based on swimming speed, default SCA settings (see below) for Fish/Invertebrate and curvilinear velocity (VCL) were used. The number of images captured and frame rate were 50 images and 100 images $\mathbf{s}^{\mathbf{- 1}}$ respectively; VCL cut-off values of $38>50-120 \mathrm{~mm} \mathrm{~s}^{-1}$ distinguish slow- (non-progressive), medium- and rapidswimming spermatozoa. Sperm swimming ,38 $\mathrm{mm} \mathrm{s}^{\mathbf{- 1}}$ were considered to be immotile (potential flow, Brownian movement and collisions of motile spermatozoa with immotile spermatozoa). All microscopic analysis measuring the motility populations was performed using SCA version 5.4.0.0 or 6.2.0.16 (Microptic S.L.). Motility parameters of flush slides were assessed at $10 \mathrm{~min}$, whereas swim-up samples were assessed after incubation times of 10 and 60 min. 'Incubation' in this case refers to the time that swim-up spermatozoa were exposed to sea water after swim-up. The slides (Leja 20-mm deep chambered slides) were viewed using a Basler A312fc digital camera (Microptic), mounted (C-mount) on either a Nikon E50i microscope or an Olympus $\mathrm{CH} 2$ microscope, both equipped with negative phase contrast objectives used (Maree and van der Horst 2013). Two to five fields were captured randomly to eliminate bias towards best motility areas. The SCA systems automatically determine the sperm concentration of the fresh diluted sample using a Leja 20-mm deep slide (calibrated).

The following kinematic parameters were assessed: VCL, straight-line velocity (VSL), average path velocity (VAP), linearity (LIN), straightness (STR), wobble (WOB), amplitude of lateral head displacement $(\mathrm{ALH})$ and beat cross frequency (BCF). We also calculated DANCE as follows: DANCE 1/4 VCL $x$ ALH. Accordingly DANCE represents the two dimensional space occupied by a motile sperm during $1 \mathrm{~s}$.

\section{Statistical analyses}

MedCalc version 17.2 (MedCalc, Mariakerke, Belgium) was used for basic statistical analysis. Descriptive statistics were used to calculate the mean \pm s.d. Comparisons of sperm motility parameters among the different groups were performed using either analysis of variance (ANOVA) or the Kruskal-Wallis test with appropriate post hoc tests, such as the 
Student-Newman- Keuls' and Tukey tests. Two-sided $P, 0.05$ was considered significant.

\section{Results}

\section{Visual, subjective description of sperm behaviour}

Swimming of spermatozoa in a typical compressed helix when diluted with sea water was observed after different time intervals in all five mollusc and echinoderm species. In Pacific oyster and white and black mussels, sperm activation was delayed after dilution with sea water (either flush technique or swim-up). Full activation was usually obtained 2-7 min after dilution with sea water. In contrast $P$. angulosus and $H$. midae spermatozoa were immediately activated with sea water. The helical sperm tracks for $P$. angulosus, D. serra and $H$. midae were essentially unchanged over $1 \mathrm{~h}$, whereas in $C$. gigas and C. meridionalis most spermatozoa appeared to change their swimming behaviour from a helical progressive pattern to a more forward progressive pattern. The spermatozoa of tiger prawn were essentially immotile due to the absence of a tail or axoneme, but some kind of movement could be detected and is described later.

CASA analysis of sperm concentration and percentage and progressive sperm motility The sperm concentrations of dry spermatozoa and the percentage motility, progressive motility and nonprogressive motility in the six species within the first 5-15 $\mathrm{min}$ after dilution and activation with sea water are given in Table 2. The sperm concentration of samples from testicular origin was extremely high (ranging from $.1554 .3 \times 10^{6} \mathrm{~mL}^{-1}$ in $C$. gigas to $5057.2 \times 10^{6} \mathrm{~mL}^{-}$ 1 in $P$. angulosus (gonopore collection)) compared with spermatozoa in general. $H$. midae samples had the lowest sperm concentration, but these samples are largely representative of spermatozoa spawned in sea water via the nephridiopore into surrounding sea water (i.e. spermatozoa collected while animals were spawning in tanks). After flush or swim-up, the sperm concentration in the other four species (excluding $H$. midae) varied from approximately 15 to $30 \times 10^{6} \mathrm{~mL}^{-1}$. Accordingly, sperm motility for all species was analysed at the same range of sperm concentrations. There was a large variation in the mean percentage sperm motility, ranging from $54 \%$ to $91 \%$ among the broadcast spawning species.

\section{CASA analysis of sperm motility patterns}

Fig. 1 shows a collage of the swimming patterns analysed by means of CASA in five species soon (5-15 min) after sperm activation, as well as the motility patterns after $60 \mathrm{~min}$. The pattern for each species is shown at the same magnification, with $P$. angulosus clearly having the largest helical diameter for the sperm tracks (30-70 $\mathrm{mm}$ (50th percentile)) and C. gigas smallest (9-15 $\mathrm{mm}$ (50th percentile)) and the other species having helical tracks with diameters intermediate between these two above extremes (Fig. 2). Despite diameter and kinematic differences (see below) the actual pattern of the helix is quite similar in $P$. angulosus, $H$. midae and D. serra. However, in $C$. gigas there appears to be a distinctive species-specific track: a serrated helix with a very small diameter (Fig. 3). 
Furthermore, after $60 \mathrm{~min}$, the progressive helical patterns remained the same for swim-up spermatozoa of $P$. angulosus, $H$. midae and D. serra, but in C. meridionalis and C. gigas almost no helical progressive swimming spermatozoa were evident, with mostly straight line forward progressive spermatozoa (Fig. 1, white arrows). These forward progressively motile spermatozoa accounted for approximately $20 \%$ of the $D$. serra sample after $60 \mathrm{~min}$ (Fig. 1), but the helical tracks strongly prevailed in this species like in $P$. angulosus and $H$. midae. Spermatozoa collected from spawning C. meridionalis exhibited primarily helical swimming (5-60 min) in contrast with spermatozoa collected from the gravid testis, which primarily exhibited more forward progressive tracks after 60 min. However, sperm velocities (VCL, VAP and VSL) and most other kinetic parameters did not differ significantly between spermatozoa of testicular origin and 'spawned' spermatozoa. Fig. 3 shows a selection of the details of individual spermatozoa representing typical progressive helical patterns among the species, typical forward progressive-type spermatozoa and the relevant kinematics for each type.

\section{CASA sperm kinematic parameters}

Fig. 4 compares the kinematic values of sperm subpopulations (rapid, medium, slow) for each species. There are significant differences in VCL and VAP between the rapid and medium sperm populations $\left(P, 0.05, F^{1 / 4} 8.5\right)$, which emphasises the importance of the subpopulation approach when studying sperm kinematics. In $P$. angulosus, mean VCL and VAP values for the rapid sperm population are $240.7 \pm 51.9$ and $207.1 \pm 52.1 \mathrm{~mm} \mathrm{~s}^{-1}$ respectively (Fig. 4), and the VCL for individual spermatozoa can reach values .400 $\mathrm{mm} \mathrm{s}^{-1}$ at 50 frames $\mathrm{s}^{-1}$ (Fig. 2). In contrast, C. gigas, which had the smallest-diameter helical swimming, mean VCL and VAP values were $149.4 \pm 11.5$ and VAP $60 \pm 7 \mathrm{~mm} \mathrm{~s}^{-1}$, with a maximum VCL of approximately $160 \mathrm{~mm} \mathrm{~s}^{-1}$.

\section{More detailed comparisons of individual tracks in different species}

The relationships among diameter, VCL, VAP and DANCE of the helical sperm tracks (Fig. 2) were further analysed by Spearman rank correlations and refer to the total motile sperm population. Some of these correlations are given in Tables 3 and 4. Correlations when population averages for all species were combined in relation to helix characteristics are given in Table 3. For the population averages, there were highly significant positive correlations between diameter and VCL, diameter and VAP, and diameter and DANCE. The greater the diameter, the higher the positive correlation with VCL, VAP and DANCE for all species together. Accordingly, in general, when spermatozoa swim faster, the diameter of the helix increases, as does DANCE, which is an expression of the surface area space occupied by the spermatozoa during $1 \mathrm{~s}$. Because ALH x VCL $1 / 4$ DANCE, the relationship between VCL and ALH was investigated in four representative species (Table 4). Very high correlations $(r$ 1/4 0.6-0.91; $P, 0.0001, F 1 / 4$ 9.3) were established between VCL and ALH for the five species. Accordingly, increases in both VCL and ALH contribute to an increased DANCE and increased 'sperm search area'. The correlations for both population averages and individual species have implications in the spermatozoa finding an oocyte. 
Effects of egg water and hyperactivation stimulants on C. meridionalis, C. gigas and P. angulosus spermatozoa

Sperm motility patterns in $C$. meridionalis, $C$. gigas and $P$. angulosus changed when samples were diluted with egg water. In Parechinus, there was an initial (first $10 \mathrm{~min}$ ) significant inhibition of VCL and VAP $\left(P, 0.02, F^{1 / 4} 6.2\right)$ when samples were diluted in egg water compared with the swim-up procedure. In Choromytilus and Crassostrea, the sample size and thus the results for VCL and VAP were too variable to establish any differences. However, after 45-60 min exposure to egg water, there was an increase in what appears to be typically hyperactivated sperm motility patterns in $C$. meridionalis and C. gigas (Fig. $5 a, b$ ). In $P$. angulosus, the typical helical swimming pattern changed to an uneven helix pattern in egg water, with a minority of spermatozoa showing similar 'hyperactivation patterns' after $1 \mathrm{~h}$ as found in C. meridionalis and C. gigas from 5 to $60 \mathrm{~min}$ (Fig. 5c).

The effects of $\mathrm{Ca}^{2+}$ modulators caffeine and procaine hydro-chloride, which typically induce hyperactivation in many animal species, were tested on C. meridionalis and C. gigas spermatozoa. These two $\mathrm{Ca}^{2+}$ modulators induced typical hyperactivation patterns (Fig. $5 d$, e). It appears that egg water induces similar changes in sperm motility patterns to the classical hyperactivation $\mathrm{Ca}^{2+}$ modulators caffeine and procaine hydrochloride (Fig. 5).

\section{Special case of tiger prawn spermatozoa}

It was possible to accurately determine prawn sperm concentration using CASA-Mot within $5 \mathrm{~s}$. (Concentrations were measured in diluted sperm samples in a Leja slide using SCA software.) Because of the high sperm concentration, dilution with sea water was required. Sperm concentration in the tiger prawn was in the same concentration range as for broadcast spawners, namely $.1500 \times 10^{6} \mathrm{~mL}^{-1}$. In the initial CASA-Mot studies, it was noted that there was approximately $10 \%$ 'motility', but these observations were discounted because of potential Brownian movement or flow. However, using highresolution differential interference microscopy at a magnification of x600, some movement of the flexible spike attached to the acrosome (Fig. 6) was documented. Fig. 6 shows scanning and transmission electron micrographs of tiger prawn spermatozoa. In Fig. $6 b$, the basic sperm components are shown, whereas Fig. $6 c$ shows an enlarged view of the microtubule ring that seems to be able to provide movement of the acrosomal spike. It is unlikely that the spike can cause large displacement of the spermatozoa, but it may be a way of orientating spermatozoa to the eggs. 

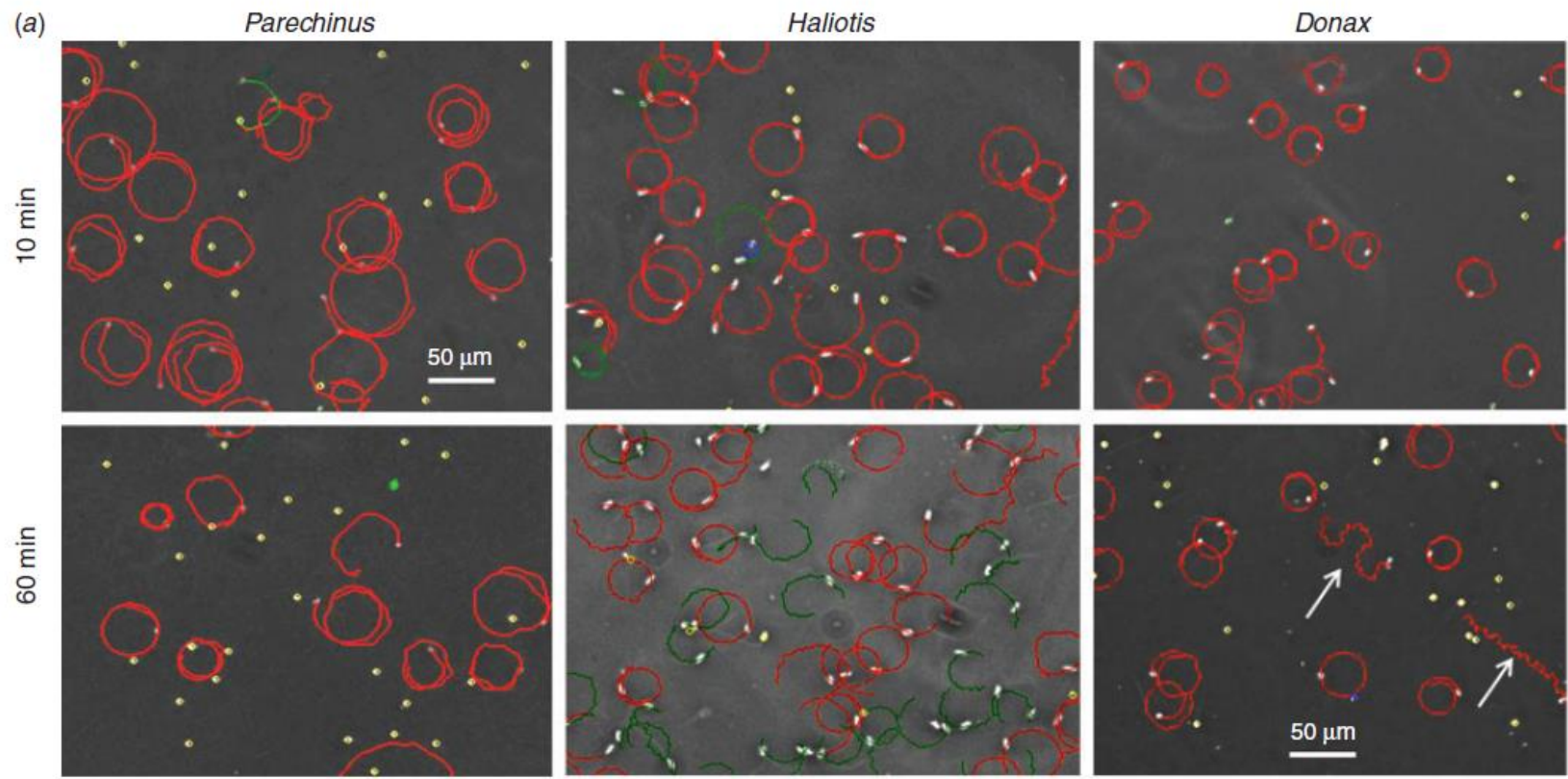

(b)
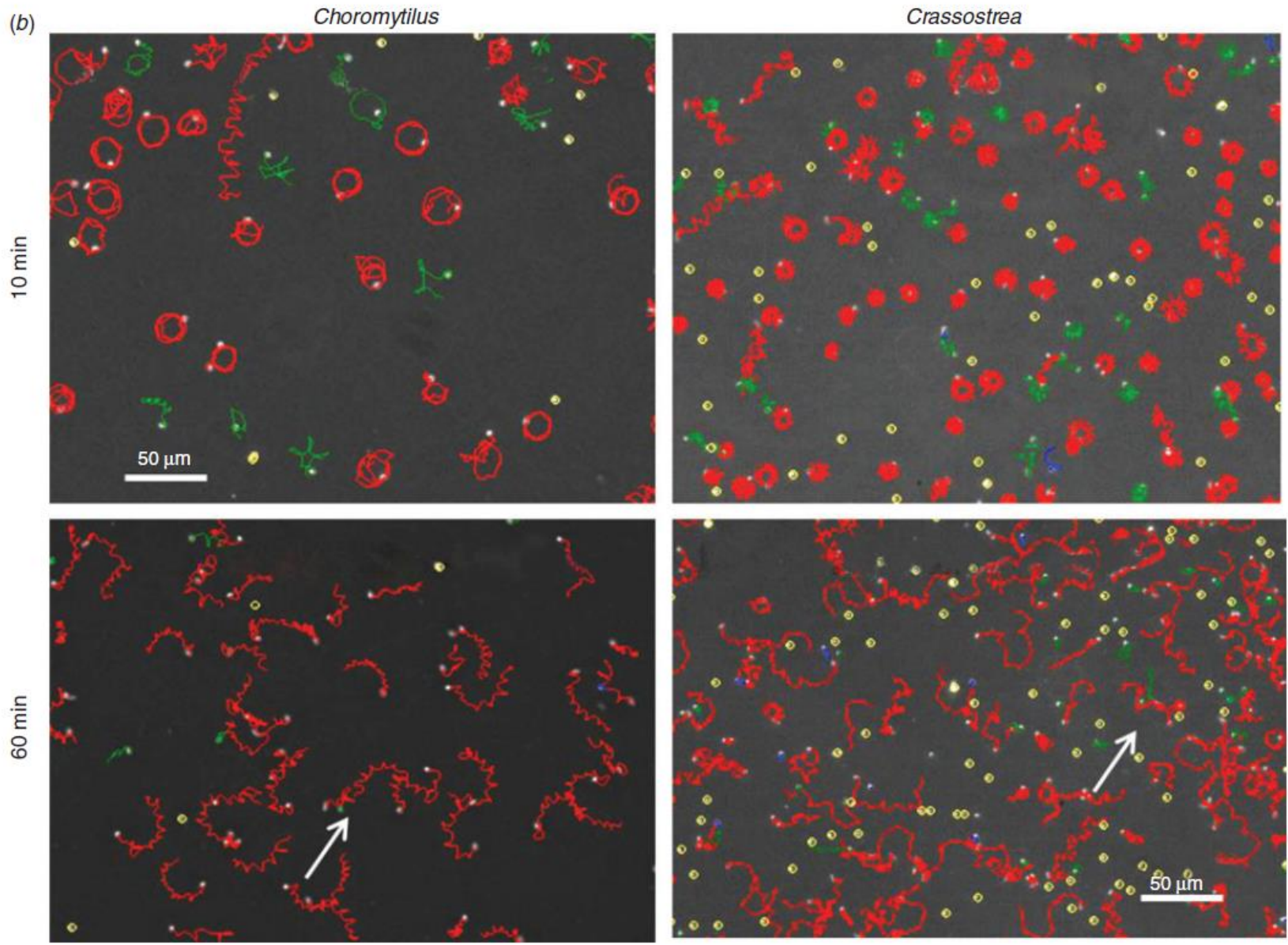

Fig. 1. (a) Characteristic sperm motility tracks of (a) Parechinus, Haliotis and Donax and (b) Choromytilus and Crassostrea 5-10 and 60 min after dilution. Scale bars apply to all figure panels. Red tracks, rapid swimming sperm; green tracks, medium swimming sperm. White arrows indicate sperm now swimming progressively forward. 

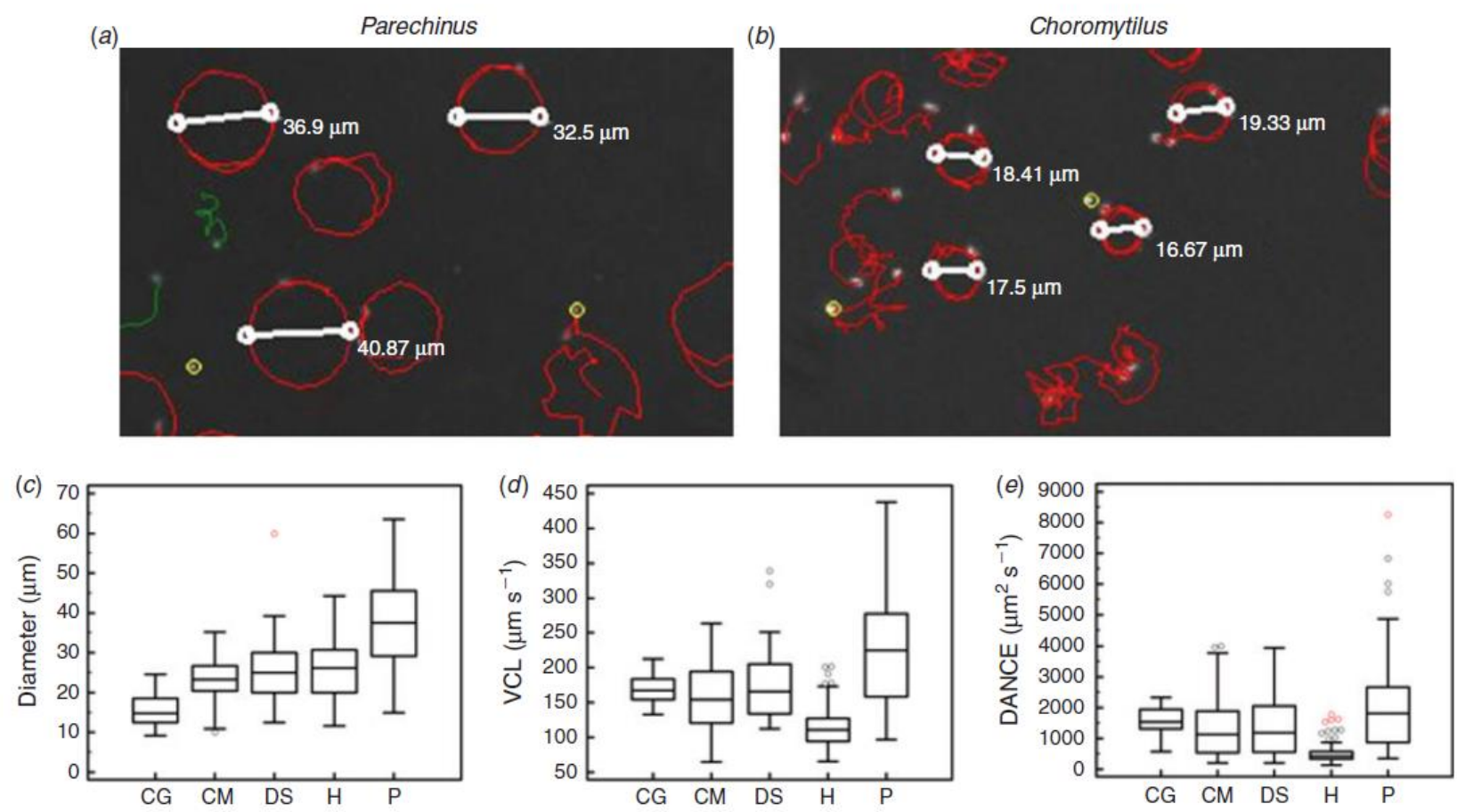

Fig. 2. ( $a, b)$ Actual measurement of the diameter of the helix in Parechinus $(a)$ and Choromytilus $(b)$. ( $(c-e)$ Box plots of the diameter of the helical tracks $(c)$ and the curvilinear velocity $(\mathrm{VCL} ; d)$ and DANCE represents the two dimensional space occupied by a motile sperm during $1 \mathrm{~s}(\mathrm{VCL} \times \mathrm{ALH} ; e$ ) for these tracks in the five species investigated in the present study. The boxes show the interquartile range, with the median value indicated by the horizontal line; whiskers show the range. Circles indicate outliers. CG, Crassostrea gigas; CM, Choromytilus meridionalis; DS, Donax serra; $\mathrm{H}$, Haliotis midae; $P$, Parechinus angulosus. The diameter of the helical tracks and VCL of Parechinus differed significantly from those of the other four species $(P<0.05)$.

Special case of insects with motile spermatozoa: desert ant, honeybee and fruit fly spermatozoa The first author (GvdH) has access to video clips of desert ant spermatozoa (Pearcy et al. 2014), honeybee spermatozoa from Morocco (Microptic) and fruit fly spermatozoa (in the female reproductive system; Professor Scott Pitnick). Desert ant spermatozoa swim in groups of 50-100 with their heads glued together at the anterior end, with individual spermatozoa coming loose. In this ant species, as well as in honeybee and fruit fly, the spermatozoa seem to clearly exhibit fairly slow helical movement and progressive forward movement. The ant work has been published (Pearcy et al. 2014) and CASA-Mot findings of honeybee spermatozoa are in the process of being published by L. W. Simmons and C. Gasparini.

\section{Discussion}

CASA-Mot analysis of five species in two invertebrate phyla of so-called broadcast spawners show helical sperm tracks similar to those described by many investigators (Levitan 1993, 1995, 1998; Au et al. 2001; Farley 2002; Riffell and Zimmer 2007; Fitzpatrick et al. 2010; Liu et al. 2011; Suquet et al. 2013; Fabbrocini et al. 2016) or at least analysed by CASAMot or objective sperm motility analysis using alternative methods (Basti et al. 2013; Lymbery et al. 2016).

There are few detailed descriptions of the nature of the patterns of these tracks, except for Liu et al. (2011) and Vogel et al. (1982), who referred to the helical tracks as 'Don Giovanni' and the forward moving tracks as 'Don Ottavio'. The implication is that theoretically there 
will be a bigger oocyte hit rate with helical swimming presumably because of the larger search area per volume. Farley (2002) correctly indicated that 'most investigators measure sperm swimming velocity without accounting for the helical motion of sperm, thereby obtaining an inflated estimate of the velocity with which sperm approach eggs'. During helical swimming, spermatozoa seem to collide more quickly with an oocyte provided oocytes are not further than $100 \mathrm{~mm}$ apart. This hypothetical distance of $100 \mathrm{~mm}$ is debatable because Roux et al. (2014) found that optimal fertilisation and hatch rates of embryos of $H$. midae (.90\%) under controlled aquaculture conditions are attained when the sperm concentration is between $5 \times 10^{3}$ and $5 \times 10^{4}$ spermatozoa $\mathrm{mL}^{-1}$ and the egg density is only approximately 50 eggs $\mathrm{mL}^{-1}$.

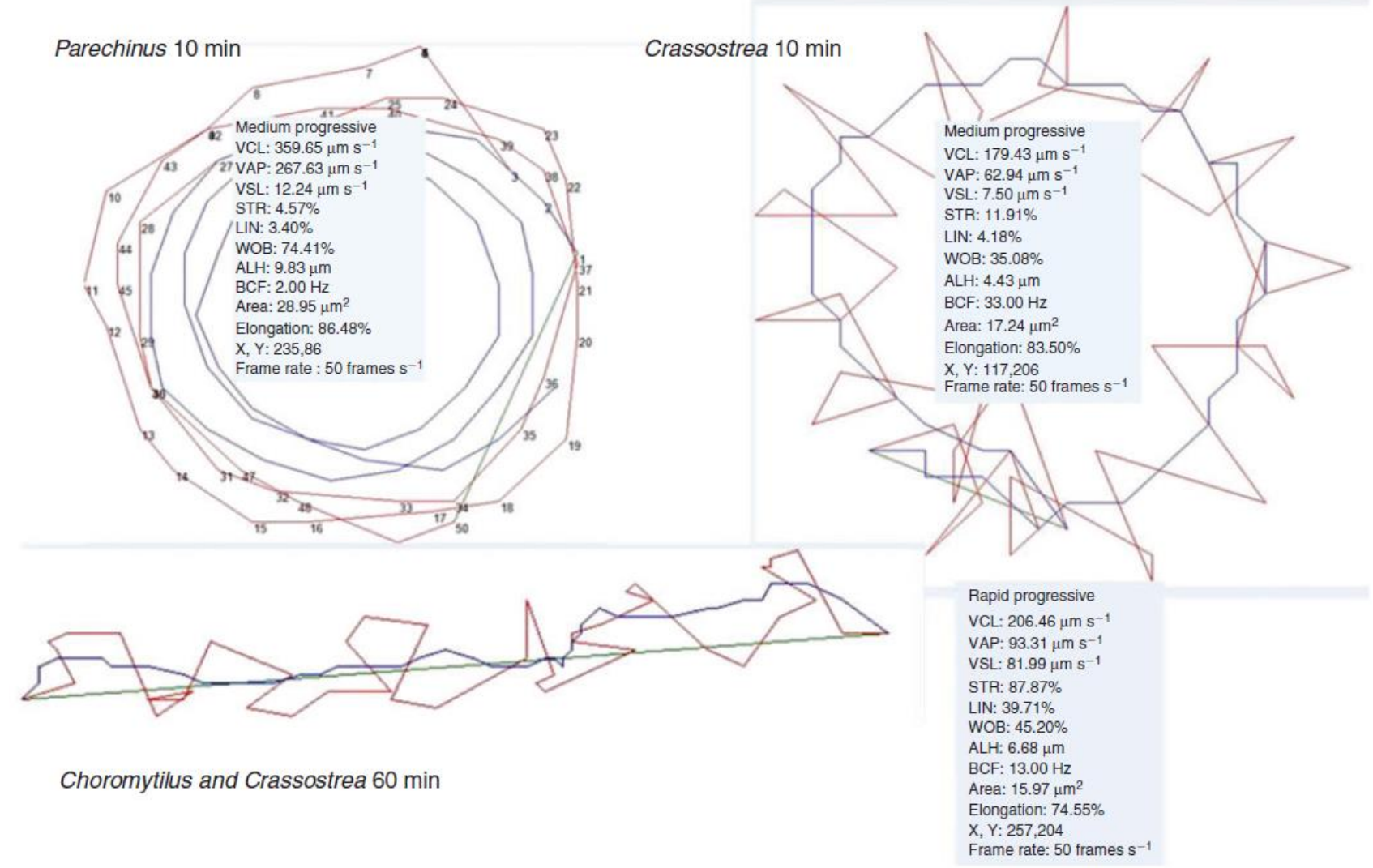

Fig. 3. Detail of characteristic sperm motility tracks in four species showing eight kinematic parameters. Red, curvilinear velocity (VCL); blue, average path velocity (VAP); green, linearity (LIN). Sperm were recorded at 50 frames per second. Accordingly, from one number to the next in the diagram for Parechinus represents one-fiftieth of a second. In all five species (four shown here), spermatozoa swim helically within minutes after dilution and retain helical swimming even up to $60 \mathrm{~min}$, except in Choromytilus and Crassostrea, in which most spermatozoa start to swim fast progressively forward. VSL, straight line velocity; STR, straightness; WOB, wobble; ALH, amplitude of lateral head displacement; BCF, beat cross frequency.

When the sperm concentration in $H$. midae reaches $5 \times 10^{5}$ spermatozoa $\mathrm{mL}^{-1}$, hatch rates decreased to ,70\% (Roux et al. 2014). Under natural conditions these sperm and egg numbers may change, but at least the above data may still support the importance of 
helical swimming as well as chemoattraction rather than just mathematical extrapolation of helical tracks.

The helical swimming in general also accounts for higher fertilisation rates in sea urchins according to Farley (2002). Farley (2002) states that when selecting for gamete traits there should be consideration of the helical nature of sperm swimming and variations in helix characteristics, as well as variation in egg size and number. The present study shows that in broadcast spawners such as $P$. angulosus, helix diameter is positively correlated with high VCL and VAP compared with the smaller-diameter helix with lower VCL and VAP. The rapid sperm population may have a higher likelihood of encountering an oocyte and represents the actual fast swimmers with a large-diameter helix and, for a particular species, these spermatozoa may be those that preferentially fertilise the oocytes. This approach is important in assessing aspects such as sperm competition, sperm limitation, defining sperm quality and in toxicology.

We believe that the DANCE (VCL x ALH) parameter, which provides an estimate of the space occupied by spermatozoa over $1 \mathrm{~s}$, may provide better estimates of sperm behaviour and the likelihood of reaching an oocyte than just the diameter of the helix or speed individually, and hope this is tested in future studies.

As suggested above, the characteristics of a spermatozoon's helical trajectory may affect the probability of its approach to an egg by chance. Helical motion is also believed to play a subsequent role in chemotaxis, whereby the difference in the concentration of sperm attractant on either side of the path creates a periodical signal used for orientation towards the source (e.g. Jikeli et al. 2015). The considerable spread of diameters of the helical paths reported here in a suite of broadcasting species may presumably reflect differences between the species in the exact circumstances of spawning, chemoattraction and fertilisation, although interpretation of the data in this way must await additional information. Chemotactic swimming responses to egg or tissue extracts have also been demonstrated in spermatozoa of spermcasting species of hydroid by Richard L. Miller (e.g. Miller 1973) in studies plotting sperm movements by non-computerised analysis of cine or multiple-exposure photomicrography. 

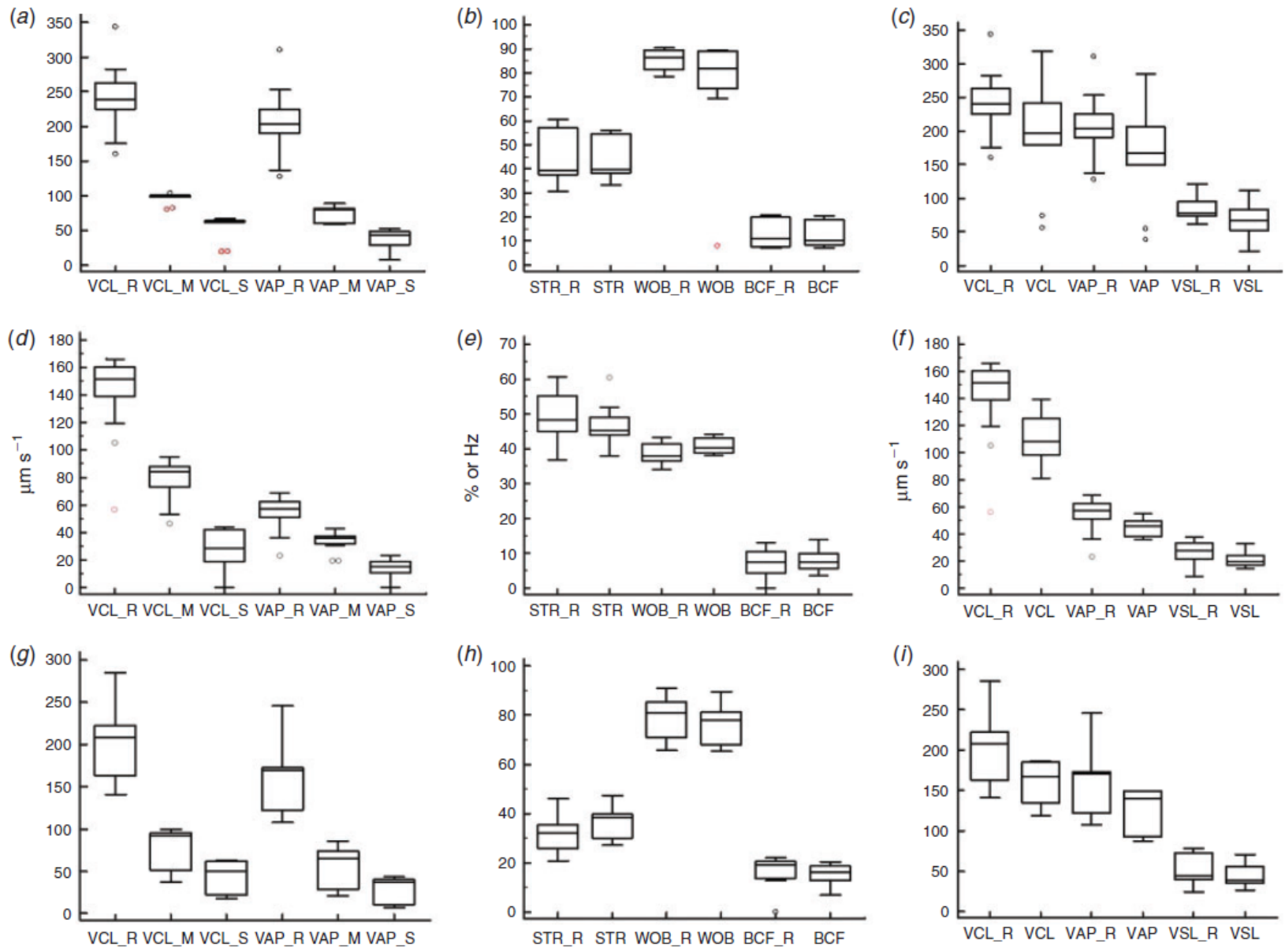

Fig. 4. Box plots showing kinematic parameters for rapid, medium and slow subpopulations of three representative species, namely $(a-c)$ Parechinus, $(d-f)$ Crassostrea and $(g-i)$ Donax. The boxes show the interquartile range, with the median value indicated by the horizontal line; whiskers show the range. Circles indicate outliers. VCL_R, curvilinear velocity (VCL) in the rapid sperm subpopulation; VCL_M, VCL in the medium subpopulation; VCL_S, VCL in the slow subpopulation; VCL, mean VCL for the entire sperm population; VAP_R, average path velocity (VAP) for the rapid sperm subpopulation; VAP_M, VAP for the medium subpopulation; VAP_S, VAP for the slow sperm subpopulation; VSL_R, straight line velocity (VSL) in the rapid sperm subpopulation; VSL, mean VSL for the entire sperm population; STR_R, straightness (STR) in the rapid subpopulation; WOB_R, wobble (WOB) in the rapid subpopulation; BCF_R, beat cross frequency (BCF) in the rapid subpopulation; STR, mean STR in the entire population; WOB, mean WOB in the entire population; BCF, mean BCF in the entire population.

Table 3. Spearman rank correlations of curvilinear velocity (VCL), average path velocity (VAP) and diameter of sperm helical tracks of all five species combined

For each species, 100 helical tracks were measured using the Measure Tool of the Sperm Class Analyser (SCA; Microptic) CASA-Mot system. DANCE was calculated as VCL $\times$ ALH

\begin{tabular}{lccccccccccccc}
\hline & \multicolumn{2}{c}{ VCL } & \multicolumn{2}{c}{ VAP } & \multicolumn{2}{c}{ Diameter } & \multicolumn{2}{c}{ Perimeter } & \multicolumn{2}{c}{ Area } & \multicolumn{2}{c}{ DANCE } \\
& $r$ & $P$-value & $r$ & $P$-value & $r$ & $P$-value & $r$ & $P$-value & $r$ & $P$-value & $r$ & $P$-value \\
\hline VCL & & - & 0.89 & $<0.0001$ & 0.41 & $<0.0001$ & 0.3 & $<0.0001$ & 0.31 & $<0.0001$ & - \\
VAP & 0.89 & $<0.0001$ & & - & 0.62 & $<0.0001$ & 0.62 & $<0.0001$ & 0.63 & $<0.0001$ & 0.68 & $<0.0001$ \\
Diameter & 0.41 & $<0.0001$ & 0.62 & $<0.0001$ & & - & -0.41 & $<0.0001$ & & - & 0.68 & $<0.0001$ \\
\hline
\end{tabular}

Hydroid spermatozoa on the surface of microscope slides moved in a circular motion, suggesting that, as with broadcasters, a helical motion would occur in deeper water, because helical three-dimensional motion becomes circular in spermatozoa constrained by a flat surface (Guerrero et al. 2011). This suggests that comparison by CASA-Mot of the characteristics of helical sperm motion between broadcasters and spermcasters may prove 
informative in relation to their adaptations for their different mechanisms of achieving fertilisation. Any distinctions may be related, in part, to the different size and nature of the 'target' to be found by spermatozoa: in broadcast spawning, this is typically an egg, whereas in spermcast spawning the spermatozoa have to reach a conspecific adult and, in many cases, will be drawn in by the feeding current.

Studies of sperm subpopulations, such as rapid sperm percentages and kinematics, to evaluate the effects of environmental factors have been rarely attempted, but Fabbrocini and D'Adamo (2011) and Fabbrocini et al. (2016) have shown the value of studying subpopulations. Mortimer et al. (2015) emphasised that population averages for sperm kinematics in humans and animals are of limited use.

Table 4. Spearman rank correlations for curvilinear velocity (VCL) and average path velocity (VAP) with amplitude of lateral head displacement (ALH) in four representative species

VCL is highly positively correlated with ALH in all species. For each species, 100 helical track diameters were measured, as indicated in Table 3

\begin{tabular}{ccccccccccc}
\hline & \multicolumn{10}{c}{ ALH } \\
& \multicolumn{1}{c}{ Parechinus } & \multicolumn{2}{c}{ Donax } & \multicolumn{1}{c}{ Haliotis } & \multicolumn{2}{c}{ Choromytilus } \\
& $r$ & $P$-value & $r$ & $P$-value & $r$ & $P$-value & $r$ & $P$-value \\
\hline VCL & 0.58 & $<0.0001$ & 0.8 & $<0.0001$ & 0.76 & $<0.0001$ & 0.81 & $<0.0001$ \\
VAP & 0.76 & $<0.0001$ & 0.315 & $<0.0001$ & 0.67 & $<0.0001$ & 0.315 & $<0.003$ \\
\hline
\end{tabular}


(a)

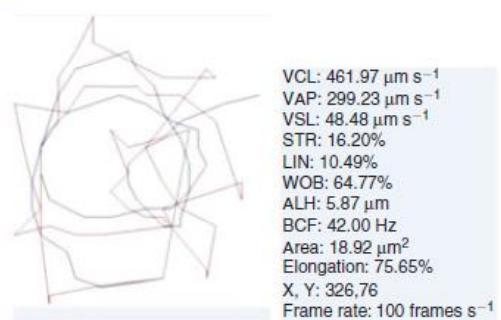

(d)

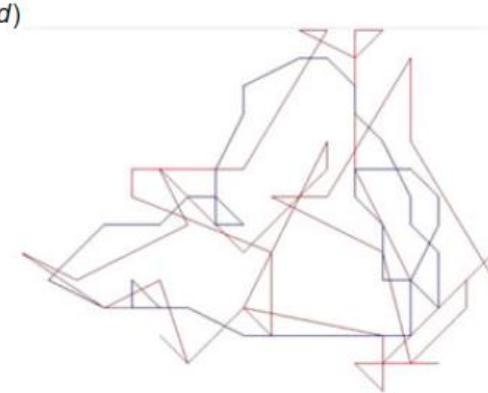

(b)

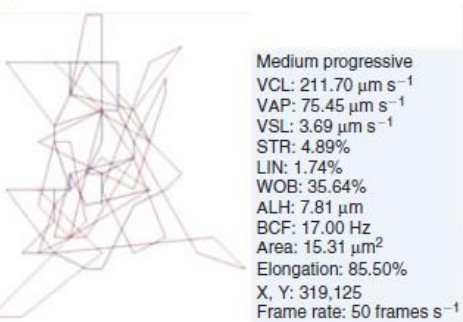

(c)

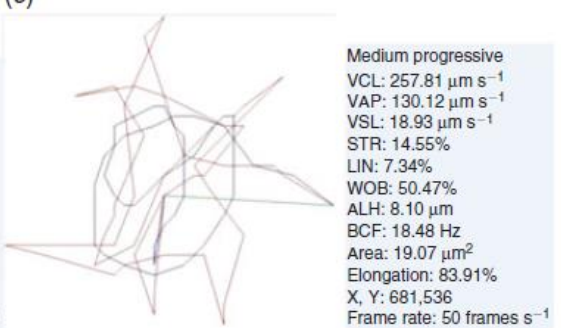

Medium progressive

VCL: $129.90 \mu \mathrm{m} \mathrm{s}^{-1}$

VAP: $59.09 \mu \mathrm{m} \mathrm{s}^{-1}$

VSL: $2.00 \mu \mathrm{m} \mathrm{s}^{-1}$

STR: $3.39 \%$

LIN: $1.54 \%$

WOB: $45.49 \%$

ALH: $4.33 \mu \mathrm{m}$

BCF: $14.70 \mathrm{~Hz}$

Area: $39.52 \mu \mathrm{m}^{2}$

Elongation: $89.31 \%$

$X, Y: 361,243$

Frame rate: 49 frames $\mathrm{s}^{-1}$

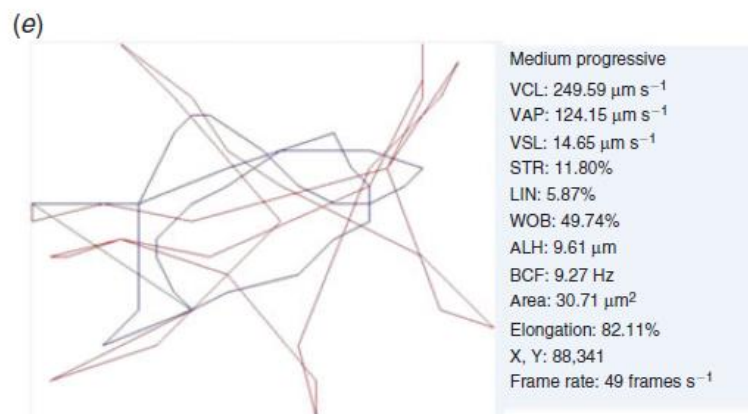

Fig. 5. Hyperactivated-like patterns of spermatozoa following activation of (a) Choromytilus, (b) Crassostrea and (c) Parechinus with egg water, (d) Choromytilus with $10 \mathrm{mM}$ caffeine in sea water and (e) Choromytilus with $5 \mathrm{mM}$ procaine hydrochloride and $10 \mathrm{mM}$ caffeine in sea water. These tracks are characterised by rapid curvilinear velocity (VCL), very large amplitude of lateral head displacement (ALH) and small linearity (LIN). VAP, average path velocity; VSL, straight line velocity; STR, straightness; WOB, wobble; BCF, beat cross frequency.

(a)

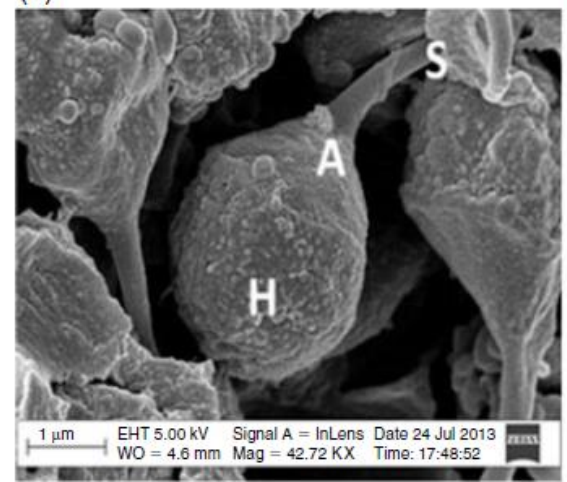

(b)

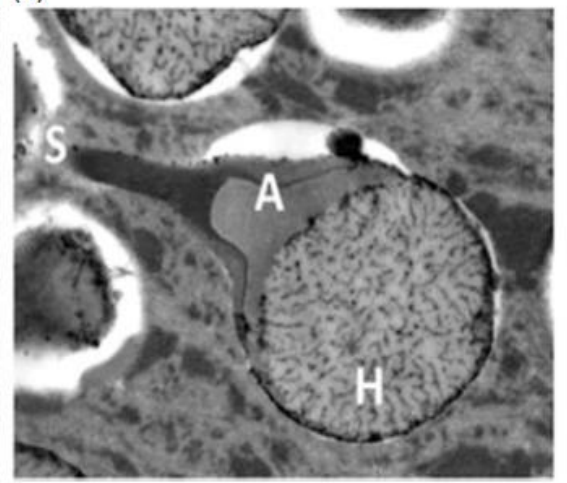

(c)

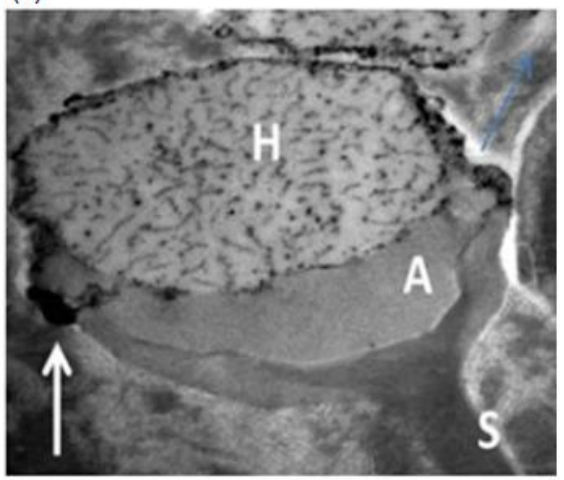

Fig. 6. (a) Scanning electron micrograph and $(b, c)$ transmission electron micrographs of tiger prawn spermatozoa. The arrow indicates the microtubular apparatus that may be involved in spike mobility. A, acrosome; $\mathrm{H}$, head; S, spike.

Unfortunately, most papers using CASA-Mot in broadcast spawners considered only averages, and this may bias interpretation of data because of the very large ranges of values for most kinematic parameters. Stewart et al. (2012) showed in a very elegant experiment that there were no differences in sperm velocities in the presence or absence of eggs. However, averages were used and, in this instance, may have 'hidden' subtle but important differences in motility subpopulations. In the present study, the pattern of sperm movement changed when spermatozoa were exposed to egg water or eggs, and spermatozoa started to show hyperactive-like patterns that could also be induced with classical $\mathrm{Ca}^{2+}$ modulators. The cation channels of spermatozoa (CatSper family of genes) responsible for hyperactivation is 
also present in most invertebrates, including cnidarians, and, accordingly, hyperactivation has been evolutionarily conserved for a long time (Cai and Clapham 2008).

Spermatozoa of testicular origin was used in the case of three species in the present study, in contrast with the use of spawned spermatozoa from $P$. angulosus and $H$. midae. However, we compared sperm motility from testicular origin versus spawned spermatozoa in $C$. meridionalis and, by and large, there were no differences except for activation time and the fact that helical sperm tracks were retained for longer (i.e. after $1 \mathrm{~h}$ ) in samples of spawned spermatozoa. Furthermore, D. serra spermatozoa of testicular origin also showed predominantly helical tracks after $1 \mathrm{~h}$. Therefore, it seems that testicular spermatozoa from gravid testes and spawned spermatozoa share similar characteristics. Care needs to be taken in terms of gonadal development and potential sperm maturation before spawning because there appear to be differences in CASA-Mot parameters in relation to testicular maturation and season (Fabbrocini et al. 2016).

Are there species-specific motility traits among broadcast spawners? The present study shows many differences in motility groupings (percentages and kinematics) among species, and most of these can be related to the form and dimensions of the helical track. Are these patterns an expression of the 'fertilisation environment' and/or do they assist in understanding reproductive strategies, such as pseudocopulation, spermcasting and broadcast spawning? $P$. angulosus occurs in rock pools in groups and as single individuals, but they are mobile. Rock pools are often isolated from the sea and wave action during low tide and, if spawning occurs in these isolated pools, it will largely represent a typical sperm broadcast scenario, as in $H$. midae, and the large helical swimming, very rapid hit-and-run, 'Don Giovanni' swimming spermatozoa may suggest sperm competition rather than sperm limitation. Levitan (2000) showed that fast swimming spermatozoa attain higher fertilisation rates than slow swimming spermatozoa, but different trade-offs exist between speed and longevity in some sea urchins.

C. gigas and, in particular, C. meridionalis inhabit a high-energy environment with large wave action. $C$. meridionalis is not mobile, but occurs at very high densities growing almost on top of each other. It is difficult to conceive how gametes will be released and fertilisation will take place in a typical broadcast mode in this turbulent environment despite the fact that the animals are closely situated. Unfortunately, no information is available on the fertilisation biology of $C$. meridionalis. All that we can currently rely on are the facts at hand in terms of sperm motility and sperm motility modulation for this species. C. gigas and $C$. meridionalis have very small helical sperm track diameters and apparently modulation of sperm motility from helical to more forward progressing can occur relatively soon after dilution with sea water. Does this perhaps imply that spermatozoa may be deposited much closer to the eggs or even that spermatozoa are somehow taken inside the mantle cavity to allow protected fertilisation? In such cases, some of the bivalves living in a high-energy environment may be making use of different ways to ensure fertilisation and present a scenario of fertilisation of non-dispersing eggs. 
Many factors may affect sperm motion, reproductive strategy and fertilisation success, and among these are the role and size of oocytes, the morphology of spermatozoa (Fitzpatrick et al. 2010) and shear forces of the environment (Riffell and Zimmer 2007) to mention a few. Many theoretical models exist to describe sperm motion in external fertilisers (Levitan 1993, 1995, 1998, 2000) and, in the process, the different trade-offs between sperm velocity, sperm concentration and egg size, among others. However, the emphasis in the present study was to dissect sperm motion in great detail using CASA-Mot to provide basic but very detailed baseline information for future investigations.

\section{Conflicts of interest}

G. van der Horst is a senior consultant for Microptic SL, manufacturers of the SCA CASA software used in the present study. However, all analyses were performed independently and the association had no bearing on the outcome.

\section{Acknowledgements}

The authors thank several aquaculture and mariculture farms that made their facilities available for sperm collection, and acknowledge support from the Comparative Spermatology Laboratory at The University of the Western Cape, Bellville. The National Research Foundation of South Africa provided financial support for the present study. 


\section{References}

Au, D. W. T., Lee, C. Y., Chan, K. L., and Wu, R. S. S. (2001). Reproductive impairment of sea urchins upon chronic exposure to cadmium. Part I: Effects on gamete quality. Environ. Pollut. 111, 1-9. doi:10.1016/ So269-7491(oo)ooo35-X

Basti, L., Nagai, K., Tanaka, Y., and Segawa, S. (2013). Sensitivity of gametes, fertilization, and embryo development of the Japanese pearl oyster, Pinctada fucata martensii, to the harmful dinoflagellate, Hetero- capsa circularisquama. Mar. Biol. 160, 211-219. doi:10.1007/SoO227- 012-2079-2

Bishop, J. D. D. (1998). Fertilization in the sea: are the hazards of broadcast spawning avoided when free-spawned sperm fertilize retained eggs? Proc. Biol. Sci. 265, 725731. doi:10.1098/RSPB.1998.0353

Bishop, J. D. D., and Pemberton, A. J. (2006). The third way: spermcast mating in sessile marine invertebrates. Integr. Comp. Biol. 46, 398-406. doi:10.1093/ICB/ICJo37

Cai, X., and Clapham, D. E. (2008). Evolutionary genomics reveals lineage-specific gene loss and rapid evolution of a sperm-specific ion channel complex: CatSpers and CatSperb. PLOS ONE 3, e3569. doi:10.1371/JOURNAL.PONE.0003569

Daly, J. M., and Golding, D. W. (1977). A description of the spermatheca of Spirorbis spirorbis (L.) (Polychaeta: Serpulidae) and evidence for a novel mode of sperm transmission. J. Mar. Biol. Assoc. U. K. 57, 219-227. doi:10.1017/Soo25315400021366

Fabbrocini, A., and D'Adamo, R. (2011). Gametes and embryos of sea urchins (Paracentrotus lividus, Lmk., 1816) reared in confirmed conditions: their use in toxicity bioassays. Chem. Ecol. 27, 105-115. doi:10.1080/02757540.2011.625931

Fabbrocini, A., Di Stasio, M., and D'Adamo, R. (2010). Computerized sperm motility analysis in toxicity bioassays: a new approach to pore water quality assessment. Ecotoxicol. Environ. Saf. 73, 1588-1595. doi:10.1016/J.ECOENV.2010.05.003

Fabbrocini, A., D’Adamo, R., Del Prete, F., Maurizo, D., Specchiulli, A., Oliveira, L. F., and Sansone, G. (2016). The sperm motility pattern in ecotoxicological tests. The CRYOEcotest as a case study. Ecotoxicol. Environ. Saf. 123, 53-59. doi:10.1016/J.ECOENV.2015.08.018

Farley, G. S. (2002). Helical nature of sperm swimming affects the fit of fertilizationkinetics models to empirical data. Biol. Bull. 203, 51-57. doi:10.2307/1543457

Fitzpatrick, J. L., Garcia-Gonzalez, F., and Evans, J. P. (2010). Linking sperm length and velocity: the importance of intramale variation. Biol. Lett. 6, 797-799. doi:10.1098/RSBL.2010.0231

Guerrero, A., Carneiro, J., Pimentel, A., Wood, C. D., Corkidi, G., and Darszon, A. (2011). Strategies for locating the female gamete: the importance of measuring sperm trajectories in three spatial dimensions. Mol. Hum. Reprod. 17, 511-523. doi:10.1093/MOLEHR/GARo42

Hahn, K. O. (1989). 'CRC Handbook of Culture of Abalone and Other Marine Gastropods.' (CRC Press: Boca Raton, FL.)

Havenhand, J. N., and Styan, C. A. (2010). Reproduction and larvae/spore types. In 'Biofouling'. (Eds S. Dü rr and J. ThomasonJ.) pp. 1-15. (Wiley-Blackwell: Chichester.) 
Jamieson, B. G. M., and Rouse, G. W. (1989). The spermatozoa of the Polychaeta (Annelida): an ultrastructural review. Biol. Rev. Camb. Philos. Soc. 64, 93-157. doi:10.1111/J.1469-185X.1989.TBoo673.X

Jikeli, J. F., Alvarez, L., Friedrich, B. M., Wilson, L. G., Pascal, R., Colin, R., Pichlo, M., Rennhack, A., Brenker, C., and Kaupp, U. B. (2015). Sperm navigation along helical paths in $3 \mathrm{D}$ chemoattractant landscapes. Nat. Commun. 6, 7985. doi:10.1038/NCOMMS8985

Johnson, S. L., and Yund, P. O. (2004). Remarkable longevity of dilute sperm in a freespawning colonial ascidian. Biol. Bull. 206, 144-151. doi:10.2307/1543638

Levitan, D. R. (1993). The importance of sperm limitation to the evolution of egg size in marine invertebrates. Am. Nat. 141, 517-536. doi:10.1086/ 285489

Levitan, D. R. (1995). The sperm limitation in the sea. Trends Ecol. Evol. 10, 228-231. doi:10.1016/S0169-5347(00)89071-0

Levitan, D. R. (1998). Sperm limitation, gamete competition and sexual selection in external fertilizers. In 'Sperm Competition and Sexual Selection'. (Eds T. K. Birkhead and A. P. Møller.) pp. 175-217. (Academic Press: London.)

Levitan, D. R. (2000). Sperm velocity and longevity trade off each other and influence fertilization in the sea urchin Lytechinus variegatus. Proc. Biol. Sci. 267, 531-534. doi:10.1098/RSPB.2000.1032

Liu, G., Innes, D., and Thompson, R. J. (2011). Qualitative analysis of sperm plane circular movement in blue mussels Mytilus edulis, M. trossulus and their hybrids. J. Exp. Zool. A Ecol. Genet. Physiol. 315A, 280-290. doi:10.1002/JEZ.674

Lymbery, S. J., Didham, R. K., Hopper, S. D., and Simmons, L. W. (2016). Mutualists or parasites? Context-dependent influence of symbiotic fly larvae on carnivorous investment in the Albany pitcher plant. R. Soc. Open Sci. 3, 160690. doi:10.1098/RSOS.160690

Manr'iquez, P. H., Hughes, R. N., and Bishop, J. D. D. (2001). Age- dependent loss of fertility in water-borne sperm of the bryozoan Celleporella hyalina. Mar. Ecol. Prog. Ser. 224, 87-92. doi:10.3354/ MEPS224087

Maree, L., and van der Horst, G. (2013). Quantification and identification of sperm subpopulations using computer-aided sperm analysis and species- specific cut-off values for swimming speed. Biotech. Histochem. 88, 181-193. doi:10.3109/10520295.2012.757366

Miller, R. L. (1973). Chemotaxis of animal spermatozoa. In 'Behavior of Microorganisms'. (Ed. A. Perez-Miravete.) pp. 31-47. (Plenum Press: London.)

Morita, M., Nishikawa, A., Nakajima, A., Iguchi, A., Sakai, K., Takemura, A., and Okuno, M. (2006). Eggs regulate sperm flagellar motility initiation, chemotaxis and inhibition in the coral Acropora digitifera, A. gemmifera and A. tenuis. J. Exp. Biol. 209, 45744579. doi:10.1242/JEB.02500

Morse, D. E., Duncan, H., Hooker, N., and Morse, A. (1977). Hydrogen peroxide induces spawning in mollusks, with activation of prostaglandin endoperoxide synthetase. Science 196, 298-300. doi:10.1126/SCI ENCE.403609 
Mortimer, S. T. (1997). A critical review of the physiological importance and analysis of sperm movement in mammals. Hum. Reprod. Update 3, 403-439. doi:10.1093/HUMUPD/3.5.403

Mortimer, S. T., van der Horst, G., and Mortimer, D. (2015). The future of computer-aided sperm analysis. Asian J. Androl. 17, 545-553. doi:10.4103/ 1008-682X.154312

Pearcy, M., Delescaille, N., Lybaert, P., and Aron, S. (2014). Team swimming in ant spermatozoa. Biol. Lett. 1o, 20140308. doi:10.1098/ RSBL.2014.0308

Pemberton, A. J., Noble, L. R., and Bishop, J. D. D. (2003). Frequency- dependence in matings with water-borne sperm. J. Evol. Biol. 16, 289-301. doi:10.1046/J.14209101.2003.00509.X

Purchon, R. D. (1977). Reproduction. In 'The Biology of the Mollusca'. 2nd edn. (Ed. R. D. Purchon.) pp. 269-332. (Pergamon Press: Oxford.) Riffell, J. A., and Zimmer, R. K. (2007). Sex and flow: the consequences of fluid shear for sperm-egg interactions. $J$. Exp. Biol. 210, 3644-3660. doi:10.1242/JEB.008516

Rouse, G. W., and Jamieson, B. G. (1987). An ultrastructural study of the spermatozoa of the polychaetes Eurythoe complanata (Amphinomidae), Clymenella sp. and Micromaldane sp. (Maldanidae), with definition of sperm types in relation to reproductive biology. J. Submicrosc. Cytol. 19, 573-584.

Roux, A., Lambrechts, H., and Roodt-Wilding, R. (2014). Development of an experimental laboratory fertilization protocol for South African abalone, Haliotis midae (Linnaeus 1758). Invertebr. Reprod. Dev. 58, 42-48. doi:10.1080/07924259.2013.802261

Stewart, D. T., Jha, M., Breton, S., Hoeh, R., and Blier, P. U. (2012). No effect of sperm interactions or egg homogenate on sperm velocity in the blue mussel, Mytilus edulis (Bivalvia: Mytilidae). Can. J. Zool. 9o, 1291-1296. doi:10.1139/Z2012-099

Suquet, M., Qué ré , C., Mingant, C., Lebrun, L., Ratiskol, D., Miner, P., and Cosson, J. (2013). Effect of sampling location, release technique and time after activation on the movement characteristics of scallop (Pecten maximus) sperm. Aquat. Living Resour. 26, 215-220. doi:10.1051/ALR/ 2013048

Vogel, H., Czihak, G., Chang, P., and Wolf, W. (1982). Fertilization kinetics of sea urchin eggs. Math. Biosci. 58, 189-216. doi:10.1016/0025-5564(82)90073-6 